\title{
E-LEARNING CONTENT DESIGN STANDARDS BASED ON INTERACTIVE DIGITAL CONCEPTS MAPS IN THE LIGHT OF MEANINGFUL AND CONSTRUCTIVIST LEARNING THEORY
}

\author{
Mohammed Kamal Afify \\ Department of Educational Technology, College of Education, \\ Imam Abdulrahman Bin Faisal University (Saudi Arabia) \\ mafify@LAU.edu.sa
}

Received November 2017

Accepted January 2018

\section{Abstract}

The present study aims to identify standards of interactive digital concepts maps design and their measurement indicators as a tool to develop, organize and administer e-learning content in the light of Meaningful Learning Theory and Constructivist Learning Theory. To achieve the objective of the research, the author prepared a list of E-learning content design standards based on interactive digital concepts maps. It involved (11) general standards and (40) performance indicators. It was investigated by 21 teaching staff members who are experts in educational technology and e-learning to ration the

list and its performance indicators. Results illustrated that standards are too significant and appropriate for the purpose of the study. Results were discussed in the light of theoretical background results of researches and literature review in the field. The study provided recommendations and suggestions that can be used as practical applications in the field of developing E-learning content based on utilizing interactive digital concepts maps.

Keywords - Interactive digital concept maps, E-learning content, Meaningful and constructivist learning theory.

\section{Introduction}

Digital content used for learning in E-learning environment, greatly increased last decade. Availability and increase of digital information necessitate availability of tools which help students and teaching staff members organize and integrate e-resources effectively and search within them to achieve learning and education objectives.

At the same time, courses continuously increase online over the last decade. As a result of the increase and complexity of knowledge in various fields, many studies reported that students who have self-organization of their studies in an E-learning environment often suffer from over-cognitive load. Additionally, they may feel confused while exploration, especially when studying according to resources-based learning strategy. Consequently, there is a bad need for the tools that manage digital information in the educational contexts without exhausting the learner's working memory (Tergan, 2005a).

In this context, many researches argue that digital concept maps have met students' and teaching staff members' needs when organizing the content of digital materials. They also manage knowledge and information in Elearning environment because they allow users to search, explore, restore content from digital archives and download resources within these systems. Moreover, they provide learners a method that helps them construct obvious tracks through linked sources on concept map and control sequence organizing learning sources. In 
addition, concept maps provide flexible interface of content access and facilitate access to digital content without exhausting the learner's working memory (Kumar \& Kahle, 2006).

Digital Concept Maps is a computer-based modern tools that permit making concept map with its components, establishing hyperlinks of text or symbols in the map, establishing sub-maps, connecting among knowledge elements and providing links of information sources. Concept map is a tool of vast exploration in electronic learning environments. It's easy to disseminate it across electronic learning systems, as well. Additionally, modern applications of concept maps programs enhance cooperation among learners to build map on the internet. Researches (Royer \& Royer, 2004; Carnot, Gaudet \& Hinesley, 2006; Teo \& Gay, 2006; Chen \& Chen, 2008) illustrate the characteristics which distinguish interactive digital concept maps as a tool to develop e-learning content from the traditional map, as follows:

Theoretical Aspect: Concept maps are an application to Ausubel's theory on meaningful learning. Concept map is a preface for learning and visual planning tool which enables learner to integrate new concepts with his knowledge structure. Novak (1998) discovered that concept maps represent constructivist learning theory; they help learners to organize and reformulate knowledge and represent what they know through learner's activity's constructive aspect which helps them build their knowledge on their own instead of depending on teacher (Novak, 1998). Concept maps are effective tools of knowledge representation; they present complex concepts in an understandable method. Moreover, they facilitate learning and education processes when learners build cognitive maps on their own (GonzalezBrignardello, 2008). Huang Chiu, Liu and Chen (2011) stated that several studies have attempted to use education and information technology to enhance achieving meaningful learning recently. They illustrated that using education technology and its tools should enable learners to involve in meaningful learning rather than achieving constructive learning.

Visual Representation: Concept maps are graphic tool of organizing information and representing it in circles, squares, lines and arrows to illustrate concepts and their relations visually. Hierarchy: Concept maps involve a hierarchy starting from the highest and the most common concepts, then the least common ones. This is based on learning hierarchical structure and the context in which it is applied. Connections and Relations: They are connections among concepts. They also show relations among them, so a comprehensive idea of content structure will be formed and reorganized in a creative method. Obvious Structure: E-content in concept map will initially have an obvious structure for learners. Digital concept map acts as an advanced organizer of concepts and topics stated in content. Learner can discover and explore this structure. Editing Easiness: Easiness of building map, its review and establishing dynamic connections. Potentiality of transferring its direction and building flexible linkages. Moreover, digital concept maps provide facilities and capabilities which the traditional ones lack. They motivate users to review or modify maps and review concepts and relations easily. Abundance: E-content, prepared by digital concept map, is abundant; it involves all types of information, such as: texts, images, animations or fixed illustrations and videos. Sequence: E-content of digital concept map is designed in a form of linked small sequences rather than extended long paragraphs. Interactivity: Concept maps provide active dynamic connections that are controlled. Also, other sources related to these connections can be controlled. Concept or element can be attached to other media, including: web page, flash animation file, PDF file, audio part and quiz. It is easy to explore the content, so learners will variously and appropriately interact with the map contents. Multimedia: Modern programs of concept maps provide simple tools that integrate animation, video and audio in digital concept map. Integrating media in theses maps provides much accuracy of learner's knowledge, allows learners to represent their knowledge comprehensively, provides illustrative advantages of audio and visual images in order to enable learners learn new concepts, enables learners to see and hear concepts and helps learner to use more senses while learning (Alpert \& Grueneberg, 2001). Self-step: Digital concept map provide learners self-step and move in map structure according to their self-speed and capabilities in learning. Flexibility: Comparing to traditional map, digital concept map has much flexibility. It can be stored, printed, sent as an attachment on E-mail and disseminated on the internet. 
Changeability: Digital concept map can be continuously modified and improved. Modern software of concept maps permits changing E-map aspects, such as: color, formatting, reformulating, highlighting some concepts and adding comments on concepts. Accessibility: All learners can access E-content in concept map easily and rapidly. Also, they can search in the map for any major or sub-concept. Cooperation: Modern software permits building or modifying digital concept map- at real timecooperatively across the web. Shareability: Digital concept map can be saved according to E-content design standards (SCORM). Thus, it can be shared, exchanged and played on various E-platforms.

These characteristics have made digital concept maps an effective tool of E-content building, presenting learning content and enhancing learning and education processes. Many researchers (Allen, SchalebenBoateng, Davey, Hang \& Pergament, 2015; Filiz, Trumpower \& Atas, 2013; Gonzalez-Brignardello, 2008; Suthers, 2005; Tergan, 2005b) handled various patterns of employing digital concept maps for learning and education purposes in e-learning environment as follows:

- Exploration method in e-learning environment; they illustrate the relation between learner, course content and scholastic program content. At the same time, they act as an advanced organizer of course various sources. They also organize all sources used by teachers and students who participate in course.

- Learning activity: they are used to enhance learner, direct him towards objectives and activities and deepen his learning. Learner builds concept map on his own; it's the most common use of concept maps in which maps are used as an introduction of building learning model. So, concept maps are utilized for achievement and positive motivational aspects (Schaal, 2010).A significant improvement is shown in the conceptual performance of children who have constructed computer-generated maps using the system compared to other childrenwho have manually drawn them. An evaluation of the interactions between concept mapping and simulations is done, demonstrating that the performance of the first group of pupils in simulations is better than that of the second group (Marqués \& Pelta, 2017).

- Expert models to represent knowledge: this use focused on learners' efforts in building concept map. It shows conceptual contact, theoretical aspects, and academic structure and relations of learning unit. These sources substantially focus on drawing the students' attention towards building knowledge network. This map permits building courses attractively.

- As an evaluative tool, concept maps are used, in this pattern, as an assessment tool focusing on learners' work and concern of evaluation process (Filiz et al., 2013).

- A tool of building cooperation: in this pattern, concept maps are utilized as a tool producing common knowledge among learners; they facilitate co-operative teamwork. They are used as a means enhancing discussion processes and negotiation among learners using communication tool. They are also used as an effective learning tool that builds cooperative knowledge among them. Concept mapping facilitates participatory intervention building by formally representing all participants' opinions, generating visual representation of group thinking, and supporting priority setting. Use of prior qualitative work increases the diversity of the represented viewpoints (Allen et al., 2015)

Based on the characteristics of digital concept maps concerning digital concept maps concerning digital E-content building, these maps are used as tools that help designers to develop hyper media digital Econtent and as exploration tools that help learners find their appropriate track using various documents. Exploration methods, provided by concept maps, improve learning programs effectiveness. Digital concept maps various advantages that enable learners to carry out various tasks which improve their performance (Cañas \& Novak, 2005). According to Buendía-García and Benlloch-Dualde (2012), the use of concept maps and patterns provide a better support to instructors in the design of their technologyenhanced learning scenarios. 
Also, Digital concept maps provide learners with many facilities related to learning and self-regulation of knowledge management. They help learners gain, organize and represent information. They also help learners with self-assessment and cognitive communication in order to build common concept or carry out a role in designing and developing a common cognitive tool. They also help with individual exploration and visual search for knowledge sources in knowledge banks and management either in contexts of sources-based learning or problems solving-based learning (Tergan, 2005b).

Due to concept maps' twofold ability to enhance learning processes and manage knowledge, they are suggested to be used in developing digital E-content involved in e-learning processes (Tergan, 2003). They are rich in economic and various tools essential for E-learning environments. They organize capabilities in two aspects: organizing knowledge and organizing learning sources. They direct learner to content and information various sources, so they should be used as learning tools in all educational processes and grades (Gonzalez-Brignardello, 2008).

\section{Statement of the problem}

Several trainers and professors used Learning Management Systems (LMS) only as a mechanism to present learning content or topics. They didn't utilize the comprehensive standards and functions of building the content across the systems, such as: disregarding skills of cognitive self-regulation, demotivating learners to managing their own learning processes and not using these tools as teach supporters which enhance the learner on request (Vovides, Sanchez-Alonso, Mitropoulou \& Nickmans, 2007). Moreover, many systems of E-learning management poorly support processes of learner's selfmotivation and guidance and achieving distinctive learning. They also don't take into account learners' previous experience, knowledge and skill (Junuz, 2009; Ajami \& Suleiman, 2014).

Studies and researches relevant to developing E-learning content verified the necessity of developing new access, strategies, methods and tools that develop E-content essential for various E-learning environments in order to contribute to two aspects:

- supporting learners in learning and self-regulation of knowledge management and assisting them to gain, regulate and represent knowledge and its self- assessment;

- Providing individual exploration and visual search for learning sources in knowledge vaults and learning content management, especially in contexts of sources-based learning;

- Regulating and reformatting knowledge and representing what they know through constructivist aspect of learners' activity which helps them to construct their own knowledge themselves instead of reliance on teacher;

- Cognitive communication to construct common understanding or design and develop common cognitive tool (Latorre et al., 2014; Doong, 2012; Hussin, Bunyarit \& Hussein, 2009; Hsu, Yeh \& Yen, 2009).

The present study objectives are criating design standards of interactive digital concepts maps as a tool to develop E-learning content and their measurement method.

\section{Questions}

1. What are E-learning content design standards based on interactive digital concepts maps?

2. What is the measurement method of achieving E-learning design standards Based on interactive digital concepts map? 


\section{Significance}

- It provides a base of knowledge based on interactive digital concept maps for learning and education purposes in E-learning environment in the light of meaningful learning theory and constructivist learning theory.

- It provides educational designers and professors' guidance on designing and developing Elearning objects (LO)or micro educational units, which are essential for developing E-learning content based on the model of interactive digital concept maps.

\section{Methodology and procedures}

The author depended on analyzing literature review to conclude interactive digital concept maps design standards as tools to develop E-learning content in the light of meaningful learning theory and constructivist theory and polled the sampling on the significance of the standards.

Sampling:

For the purpose of the present research, a Purposive sample of teaching staff members, who are experts in the field of instruction technology and specialize in the design E-learning courses in order to obtain the required and sufficient information in order to rate design standards of interactive digital concept maps and their performance indicators. Sampling consisted of (21), Distributed as follows: 5 Professor, 4 Associate Professor, 8 Assistant Professor, 4 Lecturer.

Procedures:

- Defining E-learning content design standards based on interactive digital concepts maps in light of meaningful learning theory and constructivist learning theory; Throw: Exploring literature review (Khamis, 2015) and academic studies (Hussin et al., 2009; Hsu et al., 2009) which handled standards of developing E-learning digital contentp and studies which handled characteristics of digital concept maps and their use patterns (Gonzalez-Brignardello, 2008; Kumar \& Kahle, 2006; Tergan, 2005b; Cañas \& Novak, 2005; Tergan, 2003; Royer \& Royer, 2004); studies which handled principles of meaningful learning theory and constructivist learning theory and their characteristics (Karppinen, 2005; Grabe \& Grabe, 2007; Huang et al., 2011) to define theoretical principles of presenting interactive digital concept maps.

The present study, standards and characteristics of developing E-content based on digital concept maps in the light of meaningful learning theory and constructivist learning theory, was classified into three main fields and eleven main standards as follows:

- Standards of building digital concept map content: They involve standards related to the structure of concept map content, such as: 1. Standards of content organization and arrangement. 2. Standards of hierarchical structure of concepts and relations. 3. Standards of content structure. 4. Standards of links and connections.

- Standards of designing and developing digital concept map content: they involve standards related to designing concept map elements and interaction and cooperation and visual presentation method. They involve standards related to 5.Illustrations, 6. Text, 7. Exploration and hyperlinks, 8. Providing interaction and cooperation, 9. Mapaesthetics.

- Standards of displaying and organizing digital concept map content: they involve standards related to the method of displaying and organizing digital concept map content. They also involve standards related to: 10. Organizing content display. 11. Display accuracy and aesthetics. 
- Preparing a list of E-learning content development and design standards based on interactive digital concept maps; was prepared as follows:

- A general standard that handles an aspect of learning designs concerning interactive digital concept maps.

- Sub-standards of general standard. They involve some criteria or performance indicators.

- Criteria or performance indicators used to measure achieving a specific standard of learning design concerning interactive digital concept maps.

- Standards list was distributed, in the second semester of the academic year 2015/2016, to the participants to express their opinions on the significance of the proposed standard for the quality of interactive digital concept maps and their measurement indicators. Accordingly, Resulted were illustrated and analyzed.

\section{Results}

In this section, the author answers his questions according to analyzing response results of the sampling on the rate list proposed to define the significance of E-learning content based on interactive digital concept maps and their measurement indicators.

1. Answering the first question, "What are E-learning content design standards based on interactive digital concepts maps and their significance?

To answer this question, response means of each standard's significance rate among digital concept maps design standards and each indicator's significance rate of standard measurement were estimated according to significance rates as follows: (extremely significant $=5$, very significant $=4$, significant $=3$, quite significant $=2$, fairly significant $=1$, insignificant $=0$ ). This was conducted after presenting the proposed deign to sampling. Table 1, 2 and 3 shows the results: 


\section{Domain of Evaluation: Structure of Interactive digital concept maps}

\begin{tabular}{|c|c|c|}
\hline General Standard & Indicators & Mean \\
\hline \multirow{4}{*}{$\begin{array}{l}\text { 1.Interactive digital concept map } \\
\text { hierarchically arranges and } \\
\text { organizes concepts to show their } \\
\text { relations with one another }\end{array}$} & 1.1. Main concept in the map is well-defined. & 4.83 \\
\hline & $\begin{array}{l}\text { 1.2. All main and sub-concepts are carefully selected, connected } \\
\text { to the main concept and enhance it. }\end{array}$ & 4.86 \\
\hline & $\begin{array}{l}\text { 1.3. Concepts have sequences and their logical linkage make them } \\
\text { meaningful. }\end{array}$ & 4.54 \\
\hline & $\begin{array}{l}\text { 1.4. Concepts arrangement illustrates the comprehensive } \\
\text { understanding of relations among them. }\end{array}$ & 4.42 \\
\hline \multirow{3}{*}{$\begin{array}{l}\text { 2.Hierarchical structure of } \\
\text { Interactive digital concept map } \\
\text { indicates relations among concepts } \\
\text { and relates them to true } \\
\text { connections }\end{array}$} & $\begin{array}{l}\text { 2.1. Structure isn't linear and presents an obvious display of } \\
\text { essential ideas. }\end{array}$ & 4.37 \\
\hline & $\begin{array}{l}\text { 2.2. Hierarchical connection of concepts ranges from the most to } \\
\text { the least complicated. }\end{array}$ & 4.41 \\
\hline & $\begin{array}{l}\text { 2.3. Relations among main concepts and components and } \\
\text { elements of sub-concepts are obvious and hierarchical. }\end{array}$ & 4.57 \\
\hline \multirow[t]{6}{*}{$\begin{array}{l}\text { 3.Interactive digital concept map } \\
\text { considers content clarity, accuracy, } \\
\text { conciseness and update }\end{array}$} & $\begin{array}{l}\text { 3.1. Relevance: Map content is relevant to the topic; it avoids } \\
\text { presenting different views on the concept (content) that make } \\
\text { learner feel bored and confused. }\end{array}$ & 4.69 \\
\hline & $\begin{array}{l}\text { 3.2. Obviousness: All information involved in the map is obvious, } \\
\text { brief and easy. Ambiguous concepts or connecting words which } \\
\text { confuse leaner aren't used. }\end{array}$ & 4.72 \\
\hline & $\begin{array}{l}\text { 3.3. Information in concept map is accurate. Content doesn't } \\
\text { involve spelling or grammatical mistakes. }\end{array}$ & 4.81 \\
\hline & $\begin{array}{l}\text { 3.4. All information essential for concept map is available and } \\
\text { provides a high standard of comprehension. Map involves more } \\
\text { than (25) significant sub-terms and concepts which are relevant to } \\
\text { the specific topic. }\end{array}$ & 4.78 \\
\hline & $\begin{array}{l}\text { 3.5. Concept map content illustrate essential information and } \\
\text { concepts are briefly demonstrated. }\end{array}$ & 4.67 \\
\hline & 3.6. Concept map content involve new information. & 4.84 \\
\hline \multirow{4}{*}{$\begin{array}{l}\text { 4.Linkages and connections in } \\
\text { Interactive digital concept map } \\
\text { logically and correctly show } \\
\text { relations among concepts. All } \\
\text { connecting words among concepts } \\
\text { are expressive and purposeful. } \\
\text { They accurately describe relations } \\
\text { among concepts. Arrows } \\
\text { directions are accurately used to } \\
\text { illustrate ideas flow. }\end{array}$} & $\begin{array}{l}\text { 4.1. All relations among concepts are connected through } \\
\text { connecting lines which are called with connecting words. }\end{array}$ & 4.78 \\
\hline & $\begin{array}{l}\text { 4.2. Connecting lines, whose track is perfect, are logical and } \\
\text { relevant }\end{array}$ & 4.42 \\
\hline & $\begin{array}{l}\text { 4.2. Connecting words are expressive and purposeful. They } \\
\text { describe relation among concepts and terms in the map } \\
\text { accurately. }\end{array}$ & 4.57 \\
\hline & 4.4. Arrows direction is accurately used to indicate ideas flow. & 4.82 \\
\hline
\end{tabular}

Table 1. Arithmetic means of the sampling's response rate concerning each standard's significance rate of digital concept maps design standards and indicators of standard measurement in Domain:

Structure of Interactive digital concept maps

Results of Table 1 demonstrate high means of each general standard's significance rate of digital concept map design standards and its measurements criteria/ indicators. Values of arithmetic means ranged from 4.37 to 4.86 on rubrics (5 points) they are high values and are involved in the range of very high significance rate. This verifies significance of these standards in measuring the quality of interactive digital concept maps as a design tool of E-learning content in Domain: Structure of Interactive digital concept maps from the perspective of sampling. 


\section{Domain of Evaluation: Designing and Developing Interactive digital concept maps content}

\begin{tabular}{|c|c|c|}
\hline General Standard & Indicators & Mean \\
\hline \multirow{3}{*}{$\begin{array}{l}\text { 5. Drawings involved in IDCM } \\
\text { are obvious, enhance learning } \\
\text { content and help with } \\
\text { comprehension. }\end{array}$} & 5.1. Concept map drawings are appropriately used. & 4.74 \\
\hline & $\begin{array}{l}\text { 5.2. Drawings greatly enhance map topic and help with } \\
\text { comprehension. }\end{array}$ & 4.80 \\
\hline & 5.3. Drawings in the map are obvious and good. & 4.69 \\
\hline \multirow{3}{*}{$\begin{array}{l}\text { 6. Texts involved in IDCM are } \\
\text { obvious and simplify } \\
\text { understanding map content. }\end{array}$} & 6.1. Text in the map can be easily read and has appropriate size. & 4.88 \\
\hline & 6.2. Text type never exceeds three different fonts. & 4.79 \\
\hline & $\begin{array}{l}\text { 6.2. Text content matches the targeted group and has obvious letters } \\
\text { which contribute to concentration. }\end{array}$ & 4.64 \\
\hline \multirow{4}{*}{$\begin{array}{l}\text { 7.Exploration and hyperlinks in } \\
\text { IDCM correctly function, show } \\
\text { relations among concepts and } \\
\text { enrich map learning content. }\end{array}$} & $\begin{array}{l}\text { 7.1.Used hyperlinks are greatly activated to enhance the maps' terms } \\
\text { and concept }\end{array}$ & 4.89 \\
\hline & 7.2. Map's links efficiently function. & 4.88 \\
\hline & $\begin{array}{l}\text { 7.3. Used links and connections show complicated relations between } \\
\text { two concepts or more in the map. }\end{array}$ & 4.84 \\
\hline & $\begin{array}{l}\text { 7.4.Used links are various and involve various items, such as: word } \\
\text { files, PowerPoint files, audio files, video clips, illustrations and flash } \\
\text { files. }\end{array}$ & 4.67 \\
\hline \multirow{3}{*}{$\begin{array}{l}\text { 8. IDCM enables learners to } \\
\text { interact with learning content } \\
\text { and cooperate to build learning } \\
\text { content. }\end{array}$} & $\begin{array}{l}\text { 8.1. Map design enables learners to interact with its content through } \\
\text { active dynamic connections. }\end{array}$ & 4.75 \\
\hline & $\begin{array}{l}\text { 8.2. Map design enables learner to control and handle the map's } \\
\text { available sources. }\end{array}$ & 4.63 \\
\hline & $\begin{array}{l}\text { 8.3. It enables learners to cooperate and participate to complete } \\
\text { specific parts of the map concerning a specific topic on the internet. }\end{array}$ & 4.79 \\
\hline \multirow{4}{*}{$\begin{array}{l}\text { 9. Principles of visual design, } \\
\text { such as utilizing shapes and } \\
\text { colors, were kept into account } \\
\text { when designing IDCM. }\end{array}$} & 9.1. Its design is visually amazing. & 4.78 \\
\hline & 9.2. Symbols shapes don't exceed four. & 4.47 \\
\hline & 9.3. Colors are effectively used to contribute to concentration. & 4.85 \\
\hline & $\begin{array}{l}\text { 9.4. Its design highlights and focuses on the essential concepts and } \\
\text { elements. }\end{array}$ & 4.79 \\
\hline
\end{tabular}

Table 2. Arithmetic means of the sampling's response rate concerning each standard's significance rate of digital concept maps design standards and indicators of standard measurement in Domain: Designing and Developing

Interactive digital concept maps content

Results of Table 2 demonstrate high means of each general standard's significance rate of digital concept map design standards and its measurements criteria/ indicators. Values of arithmetic means ranged from 4.47 to 4.89 on rubrics (5 points) they are high values and are involved in the range of very high significance rate. This verifies significance of these standards in measuring the quality of interactive digital concept maps as a design tool of E-learning content in Domain: Structure of Interactive digital concept maps in Domain: Designing and Developing Interactive digital concept maps from the perspective of sampling.

\section{Domain of Evaluation: Displaying concept map content and its organization}

\begin{tabular}{|l|l|r|}
\hline \multicolumn{1}{|c|}{ General Standard } & \multicolumn{1}{|c|}{ Indicators } & Mean \\
\hline $\begin{array}{l}\text { 10.IDCM had a symmetrical shape, } \\
\text { involving an introduction of the } \\
\text { map. Its structure was divided into } \\
\text { meaningful parts that help learner to } \\
\text { understand its content. They had a } \\
\text { distinct form that enables learner to } \\
\text { memorize map content. }\end{array}$ & $\begin{array}{l}\text { 10.1. Presentation involves an introduction of the map's topic and } \\
\text { method of playing. }\end{array}$ & 4.61 \\
\cline { 2 - 3 } $\begin{array}{l}\text { 10.2. Content topics are divided into meaningful parts to enable } \\
\text { learners to remember concepts better. }\end{array}$ & 4.87 \\
help learner comprehend map content. & 4.81 \\
attractively displayed. & 11.1. Concept map is elaborate and main concept is easily identified. & 4.83 \\
\cline { 2 - 3 } & 11.2. The whole map is well organized. & 4.79 \\
\cline { 2 - 3 } & 11.3. Presentation is organized and stunning. & 4.85 \\
\hline
\end{tabular}

Table 3. Arithmetic means of the sampling's response rate concerning each standard's significance rate of digital concept maps design standards and indicators of standard measurement in Domain: Displaying concept map 
Results of Table 3 demonstrate high means of each general standard's significance rate of digital concept map design standards and its measurements criteria/ indicators. Values of arithmetic means ranged from 4.61 to 4.85 on rubrics (5 points) they are high values and are involved in the range of very high significance rate. This verifies significance of these standards in measuring the quality of interactive digital concept maps as a design tool of E-learning content in Domain: Structure of Interactive digital concept mapsin Domain: Displaying concept map content and its organization from the perspective of sampling.

\section{Answering the second question:"How are E-learning content design standards based on interactive digital concepts maps applied?}

Applying design quality standards of E-learning content based on interactive digital concepts maps demands utilizing accurate and easily used rating scale. The author prepared rubrics to evaluate quality of interactive digital concepts maps as a tool that develops E-learning content. Scale was built as follows:

A. Defining relative weight or relative significance of each standard whose significance is defined when evaluating E-learning content, then it's produces using interactive digital concepts maps. This is conducted using three standards (weights) as follows: main standard involving three grades (it's assigned for the standard which is too significant for the effectiveness of designing interactive digital concepts maps), very significant standard involving two grades (it's assigned for the standard which is quite significant for the effectiveness of designing interactive digital concepts maps and significant standard involving one grade (it's assigned for the standard which is fairly significant for the effectiveness of designing interactive digital concepts maps).

B. Using specific rating to help rater evaluate achievement rate of criteria standards or specific performance rates. This value is defined based on a five-point rubric as follows: Excellent $=5$ grades (it's assigned for the standard which achieves all criteria or relevant indicators), very good= 4 grades (it's assigned for the standard which achieves all criteria or relevant indicators that have different quality), good $=3$ (it's assigned for the standard which achieves from $50 \%$ to $75 \%$ of criteria or relevant indicators) poor $=2$ (it's assigned for the standard which achieves from $25 \%$ to $50 \%$ of criteria or relevant indicators), acceptable $=1$ (it's assigned for the standard which achieves from $25 \%$ of criteria or relevant indicators) and unfulfilled $=0$ (it's assigned for the standard which isn't achieved).

C. Estimating total rate of standards list which equals total of (main standard relative weight $x$ Performance standards rate; list of interactive digital concepts maps design standards involved (110 general standards and (40) performance indicators. Maximum grade of evaluation list related to interactive digital concepts maps $=(11 \times 3 \times 5)=165$ relative to the highest rate; it equals lowest rate of evaluation list related to interactive digital concepts $=(11 \times 1 \times 1)=33$ relative to the lowest rate of interactive digital concepts design standards. Thus, interactive digital concepts design standards list is appropriate for evaluating quality of developing E-learning content based on interactive digital concepts maps.

\section{Discussion}

Results demonstrated building a list of interactive digital concepts maps design standards as a tool of Elearning content design. It consists of (11) general standards and (40) performance indicators. They are highly significant according to sampling's opinions. These standards and their performance indicators agree with literature review and previous researches which handled characteristics and use patterns of interactive digital concepts maps (Gonzalez-Brignardello, 2008; Kumar \& Kahle, 2006; Tergan, 2005b; Cañas \& Novak, 2005; Tergan, 2003; Royer \& Royer, 2004).

Faculty members -the research sample- emphasize the importance of providing a new proposal of design and developing E-learning constant based on digital concepts maps. Because it enables learner and teacher to build their own digital content, organize content and establishing a structure involving all content concepts. When tackling any concept or item, details and various characteristics are displayed in a new 
window. It also focuses on the content exploration design and designs an interface and its organization in a way that motivates learning, connecting concrete objects and organizing the various E- options and exploration lists.

Proposed design standards focused on building digital concept maps as tools that provide interactive Econtent which enables learners to interact variously and appropriately through active dynamics connections which facilitate exploration in map content. Also, they as well as the other sources related to them can be controlled. They facilitate meaningful learning; they act as a model which organizes knowledge. They organize learning sources in E-learning; they direct learner towards content and information various sources. They also manage information in sources-based learning contexts. They enhance cooperation; learners can share in designing a concept map of a specific topic based on digital concept maps which permit its collaborative design on the internet.

The present study contributes to the current literature through utilizing interactive digital concepts maps as a tool to develop and design e-learning content, utilizing (11) general standards and (40) performance indicators to design Micro E-course or learning unit based on interactive digital concept maps, and designing hyper media to help learners explore and find their appropriate track. Exploration methods based on digital concept maps improve the effectiveness of learning programs. Also, the current study suggests conducting more researches to identify the impact of various patterns of digital concept maps, which are used as a tool to develop interactive digital content, on variables related to: leaner's mental capability, self-organization skills and metacognition skills.

\section{Declaration of Conflicting Interests}

The author declared no potential conflicts of interest with respect to the research, authorship, and/or publication of this article.

\section{Funding}

The author received no financial support for the research, authorship, and/or publication of this article.

\section{References}

Ajami, K., \& Suleiman, M. (2014). Evaluating Interactive Learning Content in an eLearning Environment. E-Learn Magazine, 6, 4.

Allen, M., Schaleben-Boateng, D., Davey, C.S., Hang, M., \& Pergament, S. (2015). Concept mapping as an approach to facilitate participatory intervention building. Progress in Community Health Partnerships, 9(4), 599-608. https://doi.org/10.1353/cpr.2015.0076

Alpert, S.R., \& Grueneberg, K. (2001). Multimedia in Concept Maps: A Design Rationale and Web-Based Application. Proceedings of ED-MEDIA 2001, World Conference on Educational, Multimedia, Hypermedia and Telecommunications.

Buendía-García, F., \& Benlloch-Dualde, J.V. (2012). Concept maps and patterns for designing learning scenarios based on digital-ink, technologies. International workshop on evidence-based technology enhanced learning (pp. 27-35). Berlin, Heidelberg: Springer. https://doi.org/10.1007/978-3-642-28801-2_4

Cañas, A.J., \& Novak, J.D. (2005). A concept map-centered learning environment. Paper presented at the Symposium at the 11th Biennial Conference of the European Association for Research in Learning and Instruction (EARLI), Cyprus.

Carnot, M.J., Gaudet, L., \& Hinesley, G. (2006). Using Cmap Tools for assessment mapping and planning. In A.J. Canas \& J.D. Novak (Eds.), 1, Concept Maps: Theory, Methodology, Technology: Proceedings from the Second International Conference on Concept Mapping, 2 , 275-278.

Chen, H.H., \& Chen, K.J. (2008). Using concept maps methodology to design an e-learning platform via integration of knowledge management, instruction and learning. In Computer Supported Cooperative Work in Design IV (pp. 545-554). Berlin, Heidelberg: Spinger. https://doi.org/10.1007/978-3-540-92719-8_49 
Doong, J.G. (2012, August). Exploring Humanity-Oriented Content Producing Process in Providing Valuable E-learning Applications. In Proceedings of the 2012 Sixth International Conference on Genetic and Evolutionary Computing (pp. 389-392). IEEE Computer Society. https://doi.org/10.1109/ICGEC.2012.91

Filiz, M., Trumpower, D., \& Atas, S. (2013). The Contributions of Digital Concept Maps to Assessment for Learning Practices. International Association for Development of the Information Society.

Gonzalez-Brignardello, M.P. (2008). E-Learning Uses of Concept Maps. In Proceedings of the 3rd International Conference on Concept Mapping. Retrieved from: http://cmc ihmc.us/cmc2008/cmc2008Program.html

Grabe, M., \& Grabe, C. (2007). Integrating the Internet for meaningful learning. (5th Ed.). New York: Houghton Mifflin Company,.

Hsu, C.M., Yeh, Y.C., \& Yen, J. (2009). Development of design criteria and evaluation scale for web-based learning platforms. International Journal of Industrial Ergonomics, 39(1), 90-95.

https://doi.org/10.1016/j.ergon.2008.08.006

Huang, Y.M., Chiu, P.S., Liu, T.C., \& Chen, T.S. (2011). The design and implementation of a meaningful learning-based evaluation method for ubiquitous learning. Computers \& Education, 57(4), 2291-2302. https://doi.org/10.1016/j.compedu.2011.05.023

Hussin, H., Bunyarit, F., \& Hussein, R. (2009). Instructional design and e-learning: Examining learners' perspective in Malaysian institutions of higher learning. Campus-Wide Information Systems, 26(1), 4-19. https://doi.org/10.1108/10650740910921537

Junuz, E. (2009). Preparation of the learning content for semantic e-learning environment. Procedia-Social and Behavioral Sciences, 1(1), 824-828. https://doi.org/10.1016/j.sbspro.2009.01.147

Karppinen, P. (2005). Meaningful learning with digital and online videos: Theoretical perspectives. Association for the Advancement of Computing in Education Journal, 13(3), 233-250.

Khamis, M.A. (2015). Sources of E-learning: Individuals and media. Part I. Cairo: Dar Alsehab for Printing, Publication and Distribution.

Kumar, A., \& Kahle, D. (2006). VUE: A concept mapping tool for digital content. In the Proc. of the Second Int. Conference on Concept Mapping, San José, Costa Rica, CMC.

Latorre, M., Robles-Gómez, A., Rodriguez, L., Orduna, P., San Cristóbal, E., Caminero, A.C. et al. (2014, April). A review of webapp authoring tools for e-learning. In Global Engineering Education Conference (EDUCON), 2014 IEEE (pp. 770-777). https://doi.org/10.1109/EDUCON.2014.6826181

Marqués, J.G., \& Pelta, C. (2017). Concept maps and simulations in a computer system for learning Psychology. European Journal of Education and Psychology, 10(1), 33-39.

https://doi.org/10.1016/j.ejeps.2016.07.002

Novak, J.D. (1998). Learning, creating, and using knowledge. Concept maps ${ }^{\mathrm{TM}}$ as facilitative tools in schools and corporations. Mahwaw: Lawrence Erlbaum.

Royer, R., \& Royer, J. (2004). Comparing hand drawn and computer generated concept mapping. Journal of computers in mathematics and science teaching, 23(1), 67-81.

Schaal, S. (2010). Cognitive and motivational effects of digital concept maps in pre-service science teacher training. Procedia-Social and Behavioral Sciences, 2(2), 640-647. https://doi.org/10.1016/j.sbspro.2010.03.077

Suthers, D.D. (2005, January). Collaborative knowledge construction through shared representations. In System Sciences, 2005. HICSS'05. Proceedings of the 38th Annual Hawaii International Conference on (pp. 5a-5a). IEEE. https://doi.org/10.1109/HICSS.2005.151

Teo, C.B., \& Gay, K.L. (2006). Concept map provision for E-learning. International Journal of Instructional Technology Distance Learning, 3(7), 17-32.

Tergan, S.O. (2003). Managing knowledge with computer-based mapping tools. In EdMedia: World Conference on Educational Media and Technology (pp. 2514-2517). Association for the Advancement of Computing in Education (AACE). 
Tergan, S.O. (2005a). The Use of Digital Concept Maps as Cognitive Tools for Managing Knowledge and Knowledge Resources. In AAAI Spring Symposium: Reasoning with Mental and External Diagrams: Computational Modeling and Spatial Assistance (pp. 73-76).

Tergan, S.O. (2005b). Digital concept maps for managing knowledge and information. Lecture Notes in Computer Science, 34(26), In Knowledge and information visualization (pp. 185-204). Berlin, Heidelberg: Springer. https://doi.org/10.1007/11510154_10

Vovides, Y., Sanchez-Alonso, S., Mitropoulou, V., \& Nickmans, G. (2007). The use of e-learning course management systems to support learning strategies and to improve self-regulated learning. Educational Research Review, 2(1), 64-74. https://doi.org/10.1016/j.edurev.2007.02.004

Published by OmniaScience (www.omniascience.com)

Journal of Technology and Science Education, 2018 (www.jotse.org)

\section{(c) (1) (9)}

Article's contents are provided on an Attribution-Non Commercial 4.0 Creative commons International License.

Readers are allowed to copy, distribute and communicate article's contents, provided the author's and JOTSE

journal's names are included. It must not be used for commercial purposes. To see the complete licence contents, please visit https://creativecommons.org/licenses/by-nc/4.0/. 